Abstracta Iranica Abstracta Iranica

Revue bibliographique pour le domaine irano-aryen

Volume 42-43 | 2021

Comptes rendus des publications de 2019-2020

\title{
Keelan Overton, Kimia Maleki. “The Emamzadeh Yahya at Varamin: A Present History of a Living Shrine, 2018-20"
}

Anaïs Leone

\author{
(2) OpenEdition \\ Journals \\ Édition électronique \\ URL : https://journals.openedition.org/abstractairanica/52893 \\ DOI : 10.4000/abstractairanica.52893 \\ ISSN : 1961-960X \\ Éditeur : \\ CNRS (UMR 7528 Mondes iraniens et indiens), Éditions de l'IFRI
}

Référence électronique

Anaiis Leone, "Keelan Overton, Kimia Maleki. "The Emamzadeh Yahya at Varamin: A Present History of a Living Shrine, 2018-20" », Abstracta Iranica [En ligne], Volume 42-43 | 2021, document 10, mis en ligne le 30 juillet 2021, consulté le 13 décembre 2022. URL : http://journals.openedition.org/ abstractairanica/52893 ; DOI : https://doi.org/10.4000/abstractairanica.52893

Ce document a été généré automatiquement le 13 décembre 2022.

Tous droits réservés 


\title{
Keelan Overton, Kimia Maleki. "The Emamzadeh Yahya at Varamin: A Present History of a Living Shrine, 2018-20"
}

\author{
Anaïs Leone
}

\section{RÉFÉRENCE}

Keelan Overton, Kimia Maleki. “The Emamzadeh Yahya at Varamin: A Present History of a Living Shrine, 2018-20", Journal of Material Cultures in the Muslim World, 1, 2020, p. 120-159.

1 L'extraction massive des décors de céramique des monuments ilkhānides (1256-1335) est un sujet vaste qui peut être abordé de bien des manières. À partir de l'étude d'un sanctuaire majeur de cette période, l'Imāmzādeh Yahyā à Varamine, situé dans la périphérie sud de Téhéran, K. Overton et K. Maleki proposent une approche inédite de la question. L'édifice, qui a été dépouillé de la totalité de ses revêtements au lustre métallique entre la seconde moitié du $\mathrm{XIX}^{\mathrm{e}}$ et le début du XX ${ }^{\mathrm{e}}$ siècle, est néanmoins toujours en élévation et conserve son activité à une échelle locale.

2 Après une synthèse historiographique, les deux auteurs partagent leurs récits croisés du site, entre 2018 et 2020. À partir de leurs observations conjointes et respectives, elles interrogent le parcours qu'ont mené indépendamment architecture et décors actuellement dispersés à travers le monde. Cette enquête, qui mêle traces du passé, expériences du présent et perspectives méthodologiques et pédagogiques, vise à initier plus largement une nouvelle perception à l'égard des monuments de cette période qui ont subi le même sort que le sanctuaire de Varamine. Bien qu'ils soient privés des témoignages les plus spectaculaires de leur histoire, ces lieux ont bien souvent développé une dynamique propre et ont évolué au-delà de ces seules pertes. Entre 
histoire de l'art et des collections, anthropologie et perspectives muséographiques, les auteurs situent les enjeux à venir sur un plan pluridisciplinaire afin de relier les parties d'un même tout aujourd'hui fragmenté.

\section{AUTEURS}

\section{ANAIIS LEONE}

Doctorante, Aix-Marseille Université/LA3M 